\title{
Prediksi Harga Cabai dengan Pemodelan Time Series ARIMA
}

\author{
F.N Hadiansyah \\ School of Computing, Telkom University \\ Jl. Telekomunikasi Terusan Buah Batu Bandung 40257, Indonesia \\ nurhadiansyahfikri@gmail.com
}

\begin{abstract}
Chili price is one of the food commodities that can affect the value of inflation. The price of chili that is less erratic and even tend to continue to increase at some particular time will be bad for the state and society. ARIMA modeling is one of time series model that can be used to predict the possibility of the increasing of chili price. The ARIMA model uses previous chili price data to be used as a comparison so it can predict the price of chili in the future. The data will be analyzed and made into ARIMA model, then it will be determined which ARIMA model is possible so that an efficient model for chili price will be obtained. The results of this study yielded models of ARIMA (1 21$)$, AR (1), ARI (1 2) and IMA (2 1$)$ then there are tested with goodness fit to determine the best model by using RMSE, MAPE and R-square. Based on training and testing skenerio, the best result by validation methods is ARIMA
\end{abstract}

Keywords: Time Series, ARIMA, Forecasting

\begin{abstract}
Abstrak
Harga cabai merupakan salah satu komoditas pangan yang dapat berpengaruh terhadap nilai inflasi. Harga cabai yang kurang menentu dan bahkan cenderung terus mengalami kenaikan pada beberapa waktu tertentu akan berakibat buruk bagi negara serta masyarakat. Pemodelan ARIMA merupakan salah satu model time series yang dapat digunakan untuk memprediksi kemungkinan-kemungkinan terjadinya kenaikan harga cabai. Model ARIMA menggunakan data-data harga cabai sebelumnya untuk dijadikan sebagai perbandingan sehingga dapat memprediksi harga cabai di masa yang akan datang. Data akan dianalisis dan dibuatkan kedalam beberapa bentuk model ARIMA, kemudian ditentukan model ARIMA mana saja yang memungkinkan untuk dimodelkan sehingga akan didapatkan model yang efisien untuk pemodelan harga cabai ini. Hasil penelitian ini menghasilkan 4 model yaitu ARIMA (1 2 1), AR (1), ARI (1 2) dan IMA (2 1) yang kemudian dilakukan uji kebaikan untuk menentukan model terbaik dengan menggunakan RMSE, MAPE dan R-square. Berdasarkan skenario testing dan training, diperoleh model dengan performansi yang baik adalah ARIMA
\end{abstract}

Kata Kunci: Time Series, ARIMA, peramalan

\section{PENDAhULUAN}

$\mathbf{P}$ emodelan time series banyak digunakan dalam bidang keuangan untuk peramalan atau forecasting, model time series mengamati perilaku observasi yang diambil dari waktu ke waktu secara berurutan (Wei, 2006). Pada penelitian-penelitian sebelumnya, model time series telah banyak diimplementasikan untuk memprediksi suatu observasi yang berkaitan dengan waktu, seperti Aridita (2010) yang membahas tentang prediksi penjualan baju di Boyolali dan Siana (2011) yang membahas tentang prediksi time series berbasis multivariet.

Pada penelitian ini, metode pemodelan time series digunakan untuk memodelkan harga cabai, sehingga dapat dilakukan peramalan harga cabai pada masa mendatang. Cabai merupakan salah satu komoditas pangan yang dibutuhkan dalam kehidupan sehari-hari. Faktanya kelangkaan produksi cabai menyebabkan semakin banyaknya permintaan sehingga harga cabai pun kian melonjak. Melonjaknya harga cabai yang tidak menentu 
F.N HADiAnSyAH

Prediksi Harga Cabai dengan...

menyebabkan kesulitan dalam mempersiapkan cadangan produksi apabila terjadi kelangkaan (sumber: www.liputan6.com). Informasi naik turunnya harga cabai pada waktu-waktu sebelumnya, dapat menjadi variabel baru yang dipertimbangkan dalam pemodelan time series, yang dikenal sebagai voaltilitas atau simpangan baku bersyarat terhadap waktu. Melihat permasalahan tersebut di harapkan pemodelan time series dapat digunakan dengan baik untuk memprediksi fluktuasi tren harga cabai di Indonesia, sebagai langkah antisipasi permintaan pasar.

\section{TINJAUAN PUSTAKA}

\section{A. TIME SERIES MODEL ARIMA}

Time Series merupakan kejadian-kejadian yang terjadi berdasarkan waktu-waktu tertentu secara berurutan. Forecasting dalam time series merupakan prediksi untuk memperkarakan kejadian-kejadian yang akan terjadi di masa yang akan datang berdasarkan data-data sebelumnya[1].

Salah satu model dalam time series adalah ARIMA. ARIMA sering juga disebut sebagai runut waktu BoxJenkins[4]. ARIMA biasanya digunakan untuk peramalan jangka pendek karena untuk peramalan jangka panjang, model ini memiliki ketepatan yang kurang baik karena cenderung akan datar untuk periode yang panjang[6]. Model Arima didefinisikan sebagai berikut [1]:

\section{Autoregressive Model (AR)}

Bentuk umum model autoregressive dengan orde $\mathrm{p}(\mathrm{AR}(\mathrm{p}))$ atau model ARIMA $(\mathrm{p}, 0,0)$ dinyatakan sebagai berikut:

$$
Y_{t}=\alpha_{0}+\theta_{1} Y_{t-1}+. .+\theta_{p} Y_{t-p}+e_{t}
$$

$Y_{t}=$ nilai observasi pada saat $t$

$\alpha_{0}=$ konstanta

$\theta_{p}=$ parameter autoregresive ke $p$

$e_{t}=$ nilai galat saat $t$

2. Moving Average (MA)

Bentuk umum model moving average orde $\mathrm{q}(\mathrm{MA}(\mathrm{q}))$ atau ARIMA $(0,0, \mathrm{q})$ dinyatakan sebagai berikut:

$$
Y_{t}=\theta_{0}+\theta_{1} e_{t-1}+. .+\theta_{q} e_{t-q}
$$

$\theta_{0}=$ konstanta

$\theta_{q}=$ parameter moving average ke $q$

$e_{t-p}=$ nilai galat pada saat $t-k$

3. Proses Autoregressive Moving Average (ARMA)

Model umum untuk campuran proses AR (1) murni dan MA(1) murni, misalkan ARIMA (1,0,1) dinyatakan sebagai berikut:

$$
Y_{t}=\alpha_{0}+\theta_{1} e_{t-1}+. .+\theta_{q} e_{t-q}+\alpha_{1} Y_{t-1}+. .+\alpha_{p} Y_{t-p}
$$

4. Proses Autoregressive Integrated Moving Average (ARIMA)

Apabila non-stasioner ditambahkan pada campuran proses ARMA, maka memenuhi model umum ARIMA (p, d, q) terpenuhi. Persamaan untuk kasus sederhana ARIMA (p,1,q) adalah sebagai berikut: 


$$
Y_{t}=\left(1+\alpha_{1}\right) y_{t-1}+. .+\left(1+\alpha_{p}\right) y_{p-1}+e_{t}+\theta_{1} e_{t-1}+. .+\theta_{q} e_{t-q}
$$

\section{B. ROOT MEAN SQUARE ERROR}

RMSE merupakan untuk mencari kesalahan dari rata-rata error pada observasi (Willmott dan Matsuura 2005). RMSE dapat digunakan mencari tahu seberapa besar kesalahan pada data dari model yang digunakan. RMSE dapat dijadikan sebagai indikator ketidakcocokan dalam pemodelan. RMSE dapat dicari dengan menggunakan:

$$
R M S E=\sqrt{\frac{\sum_{i}^{n}\left(\hat{x}-x_{i}\right)^{2}}{n}}
$$

$\hat{x}=$ nilai hasil forecast

$x_{i}=$ nilai observasi $k e-i$

$n=$ banyaknya data

\section{MEAN ABSOLUTE PERCENTAGE ERROR}

Pakaja (2012) menjelaskan bahwa Mean Absolute Percentage Error (MAPE) adalah kesalahan absolut pada tiap periode dibagi dengan nilai observasi yang nyata untuk periode itu. Kemudian dihitung ratarata dari kesalahan persentase absolut tersebut. Sama seperti halnya RMSE, MAPE menghitung kesalahan dari data observasi dan prediksi yang dimunculkan dalam nilai persen. Nilai MAPE dapat dihitung dengan persamaan berikut :

$$
M A P E=\left(\frac{100 \%}{n}\right) \frac{\sum_{i}^{n} x_{i}-\hat{x}}{x_{i}}
$$

D. R-SQUARED

Menurut A. Colin dan Frank (1995),R-squared adalah sebuah metode untuk model regresi linear untuk uji kebaikan dari sebuah mode. R-square bernilai 0-1, semakin nilai mendekati angka 1 maka model tersebut semakin baik. Untuk mencari nilai R-square dapat dicari dengan menggunakan

$$
R^{2}=1-\frac{\sum_{i}^{n}\left(\hat{x}-x_{i}\right)^{2}}{\sum_{i}^{n}(\hat{x}-\bar{x})^{2}}
$$


F.N HADiAnSyAH

Prediksi Harga Cabai dengan...

\section{A. DATA}

\section{FORECASTING}

Data yang digunakan adalah data harga cabai periode 1 Mei 2016 - 14 Januari 2017 sebanyak 236 data yang diambil dari http://infopangan.jakarta.go.id/publik/ yang ditunjukkan pada Gambar 1.

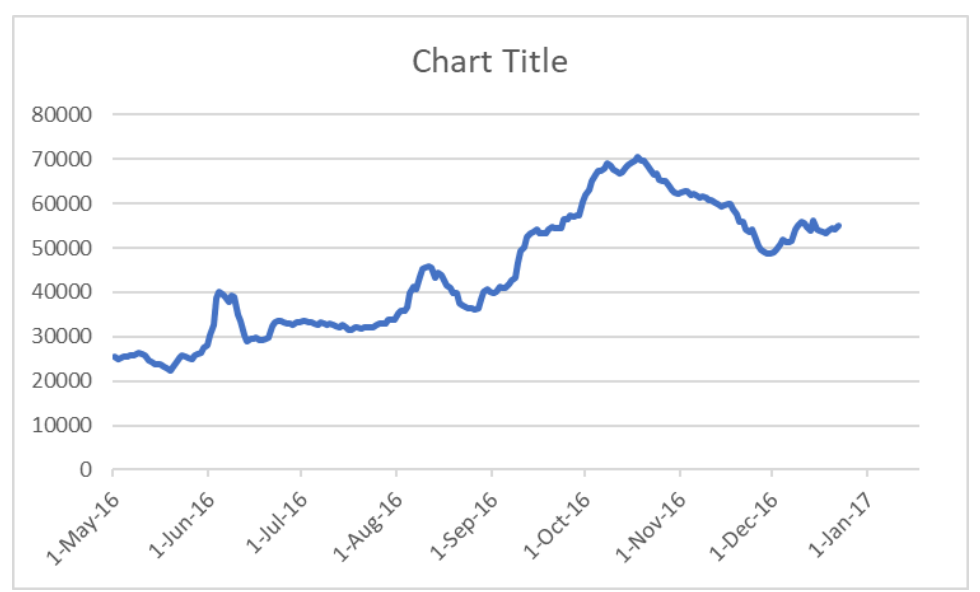

Gambar 1. Grafik time series harga cabai

Gambar merupakan grafik harga cabai dari yang diamati runtun waktu. Karakteristik pada data menunjukkan harga cabai cenderung mengalami tren kenaikan setiap periode dengan penurunan yang tidak signifikan. Dapat diperoleh perhitungan bahwa nilai variansi atau sebaran grafik tersebut tinggi, nilai variansi yang tinggi ekivalen dengan risiko yang besar. Sehingga melakukan prediksi harga cabai di masa mendatang menjadi hal yang signfikan untuk mengantisipasi kebutuhan dan risiko pasar

\section{B. PENENTUAN MODEL ARIMA}

Karakteristik pemodelan time series yang utama adalah adanya kebergantungan atau dependency observasi pada saat $t$ terhadap oservasi di waktu sebelumnya. Sehingga perlu diperhitungkan dan ditentukan batasan waktu observasi yang mempengaruhi observasi berikutnya. Untuk menentukan kebergantungan observasi pada model time series yang digunakan, ACF (Partial Autocorrelation Function) dan PACF (Partial Autocorrelation Function) pada data sehingga dapat diketahui nilai korelasi antar observasi yang menjadi batasan model time series dalam prediksi harga cabai ini.

PLOT ACF HARGA CABA

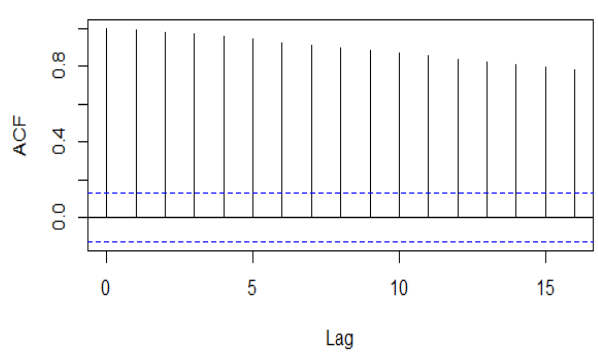

PLOT PACF HARGA CABAI

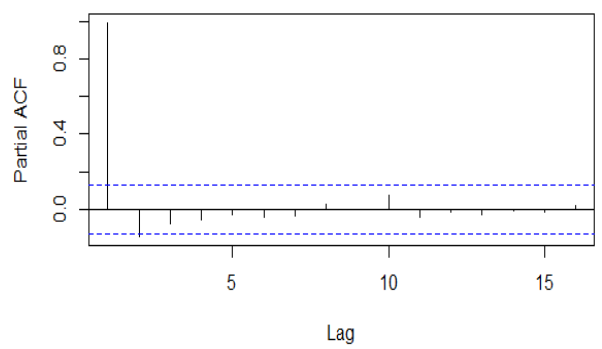

Gambar 2. Plot ACF (Autocorrelation Function) (kiri) dan Plot PACF (Partial Autocorrelation Function) (kanan) data harga cabai 
Pada Gambar 2 terlihat bahwa pada plot PACF terjadi cut off pada lag pertama, artinya observasi harga cabai hanya dipengaruhi oleh harga cabai pada satu hari sebelumnya. Hal ini mengarahkan kita pada model time series AR(1) yang melibatkan observasi sebelumnya dengan selisih waktu satu lag. Pada plot ACF tidak terjadi cut off sehingga dilakukan normalisasi data dengan menggunakan fungsi logaritma, sehingga diperoleh plot ACF dan PACF untuk data normalisasi sebagai berikut.
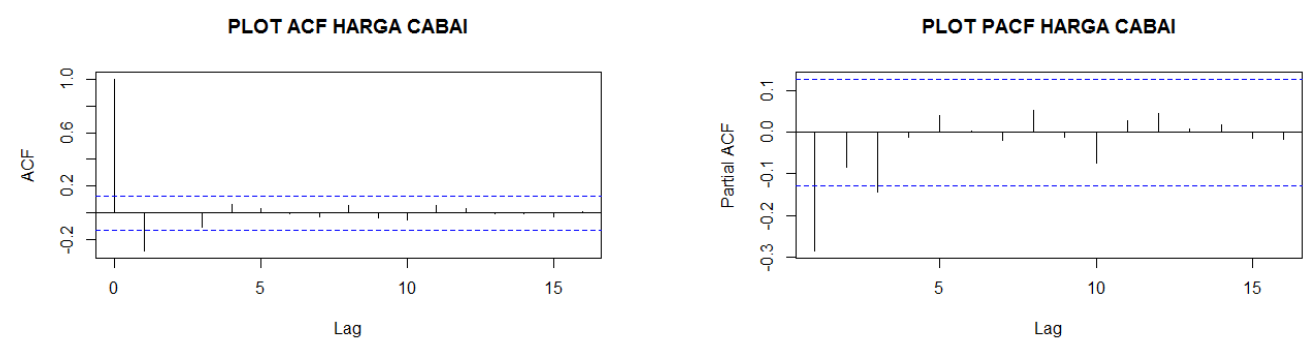

Gambar 3. Plot ACF (Autocorrelation Function) (kiri) dan Plot PACF (Partial Autocorrelation Function) (kanan) data normalisasi harga cabai

Dari Gambar 3 terlihat pada plot ACF terdapat cut off pada lag ke-2 dan pada plot PACF terdapat cut off pada lag ke-1. Hasil tersebut mengarahkan kita pada model time series dengan faktor normalisasi yang dkenal dengan integrated, yaitu model ARI $(1,2)$, IMA $(2,1)$ dan ARIMA $(1,2,1)$. Diperoleh empat model time series berdsasarkan nilai ACF dan PACF, yang selanjutnya dapat di estimasi parameter model dan diuji untuk mendapatkan model prediksi yang baik untuk harga cabai.

\section{ESTIMASI PARAMETER}

Parameter untuk model-model yang telah didapatkan dicari dengan menggunakan Maximum Likelihood Estimator. Untuk penurunan rumusnya dapat dilihat pada (Wei, 2006),

Tabel 1. Nilai Parameter Model Time Series

\begin{tabular}{|c|c|c|c|c|c|c|c|c|}
\hline \multicolumn{2}{|c|}{$\mathrm{AR}(1)$} & \multicolumn{2}{c|}{ ARI(1,1) } & \multicolumn{2}{c|}{$\operatorname{IMA}(1,1)$} & \multicolumn{3}{c|}{ ARIMA(1,1,1) } \\
\hline$\alpha_{0}$ & $\alpha_{1}$ & $\alpha_{0}$ & $\alpha_{1}$ & $\theta_{0}$ & $\theta_{1}$ & $\alpha_{0}$ & $\alpha_{1}$ & $\theta_{1}$ \\
\hline 40.8998 & 0.996968 & 0.045 & -0.556 & 0.198 & 0.994 & 0.603 & 0.444 & 0.556 \\
\hline & & & & & & & & \\
\hline
\end{tabular}

Berdasarkan parameter pada Tabel 1, maka diperoleh model-model time series untuk harga cabai sebagai berikut,

1. $\operatorname{AR}(1)$ :

2. ARI $(1,2)$

3. IMA (2 1)

$$
Y_{t}=0.00180461+0.996968 Y_{t-1}
$$

$$
Y_{t}=0.0605+0.444 Y_{t-1}-0.556 Y_{t-2}
$$

$$
Y_{t}=0.198+0.994 Y_{t-1}
$$

4. ARIMA (ll $\left.\begin{array}{lll}1 & 2 & 1\end{array}\right)$

$$
Y_{t}=0.603+0.444 Y_{t-1}-0.556 Y_{t-2}
$$

dengan menggunakan model-model tersebut, dilakukan forecasting dan validasi kebaikan model, sehingga diperoleh model yang baik untuk memprediksi harga cabai di masa mendatang. 
F.N HADiAnSyAH

Prediksi Harga Cabai dengan...

\section{HASIL DAN DISKUSI}

\section{A. FORECASTING DENGAN DATA TRAINING}

Hasil dari penelitian ini adalah untuk mencari model ARIMA mana yang lebih cocok untuk digunakan pada data harga cabai ini. Dari model yang sudah didapatkan, data dijadikan sebagai input untuk masing-masing model sehingga nilai-nilai prediksi akan keluar sebagai output dari masing-masing model tersebut. Pada Gambar 4 di tunjukan hasil dari prediksi masing-masing model yang dibandingkan dengan data observasi yang asli.
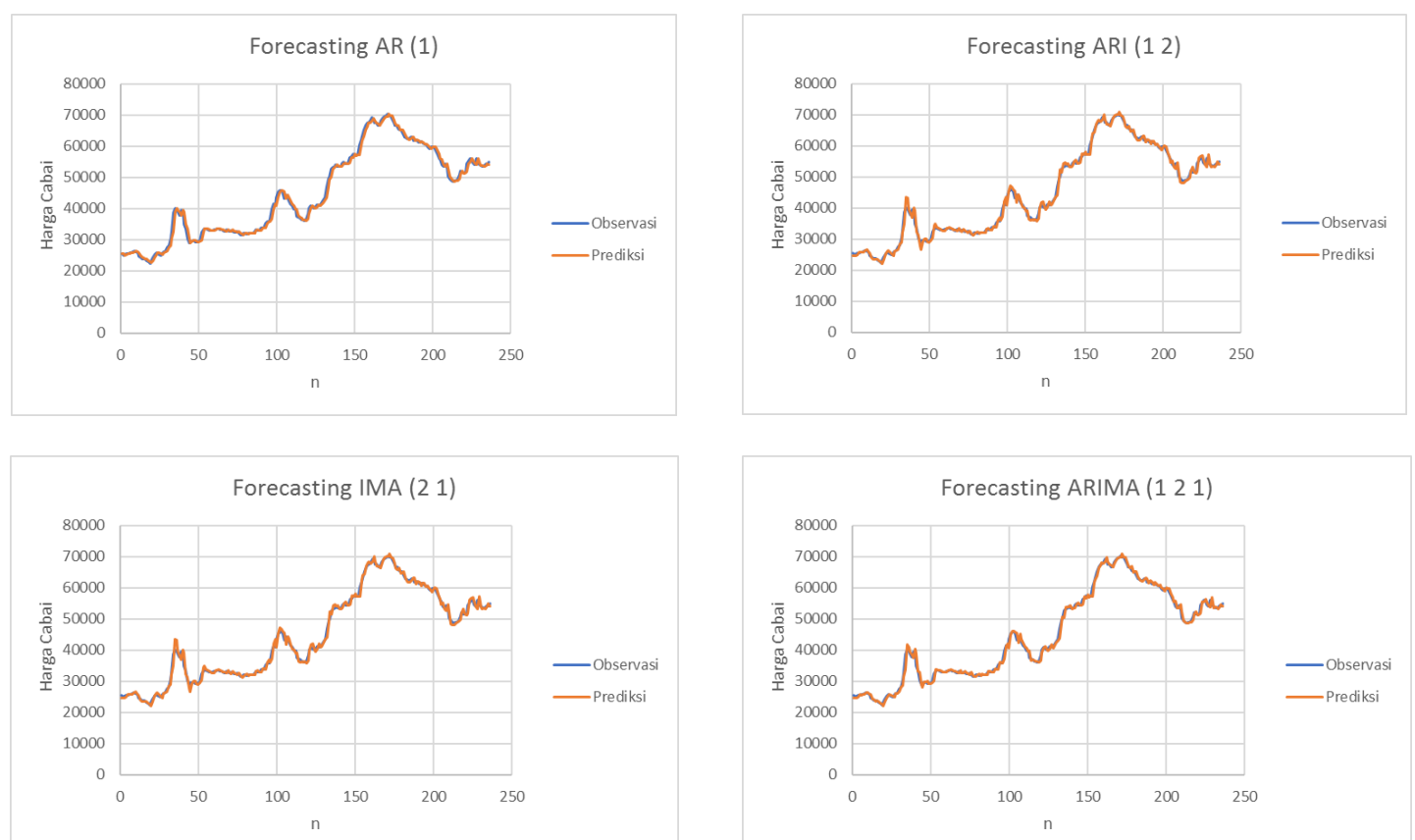

Gambar 5. Plot Data observasi dengan prediksi AR (1) (kiri atas), plot data observasi ARI (1 2) (kanan atas), plot data observasi IMA (2 1) (kiri bawah) dan Plot Data observasi dengan prediksi ARIMA (l 121$)$ (kanan bawah)

Terlihat Hasil output masing-masing model prediksi dibandingkan dengan data observasi sekilas dari ke empat model tersebut hampir sama sehingga harus dilakukan uji kebaikan untuk melihat model mana yang lebih cocok. Pada Tabel 5 di tunjukan hasil numerik dari masing-masing model yang didapatkan untuk nantinya digunakan sebagai input mencari model terbaik pada masing-masing teknik uji kebaikan yang sudah dijelaskan sebelumnya.

Tabel 2. Forecasting data training masing-masing model

\begin{tabular}{|c|c|c|l|c|l|l|l|l|l|}
\hline \multirow{2}{*}{ NO } & Tanggal & \multicolumn{2}{|c|}{ AR (1) } & \multicolumn{2}{c|}{ ARI (1 2) } & \multicolumn{2}{c|}{ IMA (2 1) } & \multicolumn{2}{c|}{ ARIMA (1 2 1) } \\
\cline { 2 - 10 } & & Data & Forecast & Data & Forecast & Data & Forecast & Data & Forecast \\
\hline 1. & $4-1-2017$ & 50795 & 48909 & 50795 & 49069 & 50795 & 48771 & 50795 & 48988 \\
\hline 2. & $5-1-2017$ & 51935 & 49414 & 51935 & 49801 & 51935 & 49541 & 51935 & 49680 \\
\hline 3. & $6-1-2017$ & 51356 & 50770 & 51356 & 51857 & 51356 & 51396 & 51356 & 51425 \\
\hline 4. & $7-1-2017$ & 51419 & 51907 & 51419 & 53157 & 51419 & 52750 & 51419 & 52469 \\
\hline 5 & $8-1-2017$ & 51682 & 51329 & 51682 & 51390 & 51682 & 51623 & 51682 & 51118 \\
\hline 6 & $9-1-2017$ & 54261 & 51392 & 54261 & 51260 & 54261 & 51608 & 54261 & 51468 \\
\hline 7 & $10-1-2017$ & 55067 & 51654 & 55067 & 51879 & 55067 & 51902 & 55067 & 51821 \\
\hline 8 & $11-1-2017$ & 55977 & 54226 & 55977 & 56025 & 55977 & 55413 & 55977 & 55445 \\
\hline
\end{tabular}




\begin{tabular}{|l|l|l|l|l|l|l|l|l|l|}
\hline 9 & $12-1-2017$ & 55617 & 55030 & 55617 & 56505 & 55617 & 56084 & 55617 & 55458 \\
\hline 10 & $13-1-2017$ & 54755 & 55938 & 54755 & 56855 & 54755 & 56954 & 54755 & 56416 \\
\hline 11 & $14-1-2017$ & 53972 & 55579 & 53972 & 55711 & 53972 & 56068 & 53972 & 55486 \\
\hline 12 & $15-1-2017$ & 56025 & 54719 & 56025 & 54076 & 56025 & 54690 & 56025 & 54396 \\
\hline 13 & $16-1-2017$ & 54244 & 53938 & 54244 & 53166 & 54244 & 53626 & 54244 & 53646 \\
\hline 14 & $17-1-2017$ & 53932 & 55986 & 53932 & 57079 & 53932 & 56627 & 53932 & 56975 \\
\hline 15 & $18-1-2017$ & 53700 & 54209 & 53700 & 53825 & 53700 & 53908 & 53700 & 53470 \\
\hline 16 & $19-1-2017$ & 53395 & 53898 & 53395 & 53105 & 53395 & 53607 & 53395 & 53815 \\
\hline 17 & $20-1-2017$ & 53886 & 53667 & 53886 & 53445 & 53886 & 53414 & 53886 & 53618 \\
\hline 18 & $21-1-2017$ & 54341 & 53363 & 54341 & 53121 & 54341 & 53103 & 54341 & 53279 \\
\hline 19 & $22-1-2017$ & 54093 & 53852 & 54093 & 54100 & 54093 & 53905 & 54093 & 54128 \\
\hline 20 & $23-1-2017$ & 55025 & 54306 & 55025 & 54814 & 55025 & 54533 & 55025 & 54567 \\
\hline
\end{tabular}

Dari Tabel 2 terlihat bahwa masing-masing model memiliki hasil prediksi yang berbeda, terlihat dari masingmasing model terdapat beberapa nilai yang hampir mendekati nilai data training pada tertentu namun terdapat juga yang perbedaan nilainya cukup jauh dengan data training sehingga diperlukan perhitungan selanjutnya untuk mencari model yang paling efisien. Untuk menentukan model yang paling efisien harus dicari terlebih dahulu nilai kesalahan untuk masing-masing model sehingga dapat ditentukan model mana yang paling baik, maka dari itu digunakan RMSE, MAPE dan R-Square seperti yang diperlihatkan pada Tabel 3,

Tabel 3. Validasi Kebaikan Model

\begin{tabular}{|l|l|l|l|l|}
\hline & AR (1) & ARI (1 2) & IMA (2 1) & ARIMA (1 2 1) \\
\hline RMSE & 1478.625 & 1052.968 & 1000.410 & 964.005 \\
\hline MAPE & $1.947 \%$ & $1.70 \%$ & $1.656 \%$ & $1.479 \%$ \\
\hline R-Square & 0.989 & 0.994 & 0.995 & 0.995 \\
\hline
\end{tabular}

Pada Tabel 3 terlihat untuk masing-masing model memiliki nilai RMSE yang berbeda untuk masing-masing model dan memiliki selisih yang cukup jauh pada masing-masing model. Model ARIMA memiliki nilai RMSE yang paling baik adalah dengan nilai RMSE yang kecil. Sama seperti halnya seperti nilai RMSE, nilai MAPE seperti yang ditunjukkan pada Tabel 7 memiliki selisih yang cukup jauh untuk masing-masing model. Model ARIMA memiliki nilai MAPE kecil yang dipilih sebagai model yang paling efisien sama seperti RMSE. Masing-masing memiliku nilai R-square yang mendekati satu, hal ini menunjukkan model time series dapat menjelaskan variable harga cabai secara signifikan dengan melibatkan observasi masa lalu (histori).

\section{B. FORECASTING DENGAN DATA TESTING}

Untuk mendapatkan model yang paling baik, dilakukan peramalan dengan data testing, dimana telah dipisahkan 10 data yang tidak dimasukan dalam pengolahan model diatas untuk mengecek tingkat akurasi dari model yang telah didapatkan seperti yang ditunjukkan pada Tabel 4,

Tabel 4. Forecasting harga cabai dengan data testing

\begin{tabular}{|c|c|c|c|c|c|}
\hline No & Data Testing & Forecast AR (1) & $\begin{array}{c}\text { Forecast } \\
\text { ARI (1 2) }\end{array}$ & $\begin{array}{c}\text { Forecast } \\
\text { IMA (2 1) }\end{array}$ & $\begin{array}{c}\text { Forecast } \\
\text { ARIMA (1 2 1) }\end{array}$ \\
\hline 1. & 32140 & 31977 & 32175 & 32175 & 32137 \\
\hline 2. & 31884 & 32163 & 32389 & 32389 & 32252 \\
\hline 3. & 32093 & 31908 & 31790 & 31790 & 31794 \\
\hline 4. & 32023 & 32116 & 32142 & 32142 & 32213 \\
\hline 5. & 32000 & 32047 & 32057 & 32057 & 32016 \\
\hline 6. & 32116 & 32024 & 31965 & 31965 & 32014 \\
\hline
\end{tabular}


F.N HADiAnSYAH

Prediksi Harga Cabai dengan...

\begin{tabular}{|c|c|c|c|c|c|}
\hline 7. & 32767 & 32139 & 32188 & 32188 & 32193 \\
\hline 8. & 33093 & 32789 & 33234 & 33234 & 33089 \\
\hline 9. & 32930 & 33114 & 33539 & 33539 & 33269 \\
\hline 10. & 32930 & 32951 & 32945 & 32945 & 32884 \\
\hline \multicolumn{6}{|c|}{ Validasi Kebaikan Model dengan Data Testing } \\
\hline \multicolumn{7}{|c|}{ RMSE } & 305.348 & 396.221 & 358.490 & 383.827 \\
\hline & RAPE & $0.651 \%$ & $0.885 \%$ & $0.712 \%$ & $0.672 \%$ \\
\hline
\end{tabular}

Sama halnya seperti hasil training, pada uji testing ini masing-masing model memiliki nilai yang berbeda dan terdapat beberapa nilai model yang hampir mendekati nilai data testing pada saat $t$ tertentu. Maka dari itu, dari hasil testing ini perlu dilakukan juga uji kebaikan model dengan teknik-teknik yang sama dengan training sebagai validasi perbandingan antara nilai training dengan testing apakah berbanding lurus atau berbanding terbalik.

\section{KESIMPULAN}

Dari hasil penelitian, untuk data prediksi harga cabai dengan menggunakan model time series ARIMA dengan data training, berdasarkan nilai RMSE dan MAPE, model yang paling baik menunjukan pada model ARIMA (1 2 1) dengan nilai RMSE 964.005 dan nilai MAPE 1.479\%. Sedangkan apabila dilihat dari nilai Rsquare, model yang paling baik menunjukan pada model IMA (2 1) dan ARIMA (1 2 1). Untuk data testing, berdasarkan nilai RMSE, MAPE dan R-Squared, model yang paling baik menunjukan pada model AR (1) dengan nilai RMSE 305.348, nilai MAPE 0.651\% dan nilai R-square 0.635. Secara keseluruhan, baik testing dan training, model ARIMA memiliki performansi yang baik untuk memprediksi harga cabai di masa mendatang, sebagai langkah antisipasi permintaan pasar yang fluktuatif.

\section{REFERENCES}

[1] Wei, W. S. 2006. Time Analysis Univariate and Multivariate Methods, New York : Addison Wesley Publishing Company, Inc

[2] Halim, Siana dan Chandra, Arief. 2011. Pemodelan Time Series Multivariat secara Automatis. Jurnal Teknik Industri Vol 13

[3] Perdana, Sukma. 2010. Perbandingan Metode Time Series Regression Dan Arimaxpada Pemodelan Data Penjualan Pakaian Di Boyolali. Surabaya

[4] Huang, Theresa. 2013. The Box-Jenkins Methodology for Time Series Models.SAS Global Forum, 2013

[5] Box, G.E.P., \& Jenkins, G.M. 1976. Time SeriesAnalysis, Forecasting and Control. HoldenDay: San Francisco.

[6] Octora, Metta \& Kunotoro. 2013. Perbandingan Metode ARIMA (Box Jenkins) dan Metode Winter dalam Peramalan Jumlah Kasus Demam Berdarah Dengue. Jurnal Biometrika dan Kependudukan, Vol. 2, No. 1 Juli 2013: 88-98

[7] Willmott J Cort dan Matsuura Kenji. 2005. Advantages of the Mean Absolute Error (MAE) Over the Root Mean Square Error (RMSE) in Assessing Average Model Performance. Department of Geography, University of Delaware. Newark USA.

[8] Pakaja, F., Naba, A., Purwanto. (2012), Peramalan Penjualan Mobil Menggunakan Jaringan Syaraf Tiruan dan Certainty Factor, Jurnal EECCIS, Vol.6, No.1, Juni 2012.

[9] A. Colin \& A.G. Frank. 1995. An R-squared measure of goodness of fit for some common nonlinear regression models.

[10] Febri, kiki; Hoyyi, Abdul \& Mukid, Adbul. 2014. Verifikasi Model Arima Musiman Menggunakan Peta Kendali Moving Range. JURNAL GAUSSIAN, Volume 3, Nomor 4, Tahun 2014, Halaman 701 - 710 . 